\title{
Editorial
}

\section{O crescimento da Revista em 2002-2003}

Com este número encerramos o ano e a gestão 2002-2003 na Revista de Psiquiatria do Rio Grande Sul. Aproveitamos este espaço para trazer ao conhecimento dos leitores o balanço das principais realizações e reflexões neste período.

Ao assumirmos como editores a Revista há dois anos, manifestávamos nossa satisfação e, ao mesmo tempo, a preocupação com a enorme responsabilidade que representa levar adiante a tarefa complexa de informar e divulgar a pluralidade do conhecimento científico psiquiátrico em nossos dias. Esta tarefa é também um desafio, pois cada um de nossos antecessores, de forma bastante efetiva, contribuiu para que a revista fosse crescendo cada vez mais, deixando-nos um vasto legado de realizações e respeitável tradição científica.

Entre as nossas principais metas e realizações podemos citar:

1. A manutenção da periodicidade. A revista vem sendo editada de forma ininterrupta durante 24 anos. Além dos três números regulares por ano, editamos de um suplemento especial dedicado aos artigos produzidos no Ciclo de Avanços em Clínica Psiquiátrica, tradicional evento que discute questões atuais da psiquiatria. Reeditamos o Roster a fim de que os sócios possam ter acesso ao cadastro de forma atualizada.

2. Publicação de artigos oriundos das mais diversas áreas da psiquiatria: clínica, forense, psicanalítica, psicoterápica, ensino e pesquisa.
Mantivemos as sessões de artigos originais, de revisão, especiais, comunicações breves, conferências, cartas, resenhas, entrevistas e criamos a sessão de saúde pública.

3. Houve um aumento significativo de encaminhamentos de artigos para avaliação do conselho editorial, reforçando nossa intenção de divulgar a revista em nível nacional. Herdamos 17 artigos da gestão anterior e recebemos um total de 98 artigos novos. Deste total, 100 artigos são de autores estrangeiros, 33 artigos originais, 10 artigos de revisão, 10 artigos produzidos no ciclo de avanços, 12 artigos diversos, 25 artigos entre recusados, retirados ou não publicados por qualquer outra razão. Deixamos 13 artigos para a próxima gestão.

3. Abertura de cotas de publicidade para divulgação da revista em nível nacional. Neste período recebemos o apoio publicitário das seguintes empresas: Lojas Colombo, Capa Engenharia, Companhia Província de Crédito e dos laboratórios, Libbs, Lilly, Bristol. Esta meta foi atingida com a absoluta preservação da independência da linha editorial da revista.

4. Aumento da tiragem de 1.000 para 5.500 exemplares com distribuição nacional aos sócios da ABP, entidades de classe e universitárias a partir de 2003. Hoje podemos dizer que a Revista de Psiquiatria é um periódico de circulação nacional com crescentes publicações de autores de distintas correntes do pensamento psiquiátrico e de diversas localidades de âmbito nacional e internacional 
5. Melhoria na qualidade de impressão sem elevação de custos.

6. Manutenção das atuais bases de dados e indexadores e inclusão em novas. Estamos no SciELO (www.scielo.br) setembro de 2003, que é uma base de dados que publicará eletronicamente a revista, possibilitando o acesso e a consulta em nível internacional via internet.

7. Criamos a Home Page da revista (www.revistapsiqrs.org.br), o fluxograma e o checklist. As instruções aos autores foram cuidadosamente revisadas e atualizadas de acordo com as novas exigências.

8. Participamos de diversos eventos como: Ciclos de Avanços, Congressos Brasileiro de Psiquiatria e de Psicanálise, Curso de editoração científica promovido pela ABEC.

Com este sucinto relato, objetivamos informar acerca de nossas principais realizações, prestar contas, possibilitando aos leitores que nos enviem comentários e sugestões para que no futuro possamos dar continuidade às metas traçadas e, principalmente, corrigir os rumos quando necessário.

É oportuno destacar que as metas e realizações atingidas são o resultado do trabalho iniciado em gestões anteriores e de uma conjunção de fatores que fazem da revista um órgão de divulgação bem sucedido. Inicialmente, salientamos o enorme entusiasmo e incansável dedicação do conselho editorial constituído por Antônio Carlos S. Marques da Rosa, Cristina Conte, Gustavo Schestatsky, Jair Knijnik, Júlio José Chachamovich, Letícia Kipper, Maria Angélica Antunes Nunes, Maria da Graça Motta, Patrícia Fabrício Lago, Patrícia Fuhro Vilas Boas e Suzana Deppermann Fortes. Ressaltamos também o crescente e estimulante interesse dos leitores e autores que nos enviam artigos, cartas e sugestões, sem os quais ficaria sem finalidade nossa razão de existir. O apoio recebido da diretoria da Sociedade de Psiquiatria do Rio Grande do Sul, especialmente representada pelo seu presidente Jair Escobar, que com seu interesse, dedicação e liderança estimulou e apoiou constantemente estas ambiciosas metas. A dedicação constante e eficiência no trabalho de nossa secretária Sandra Maria Schmaedecke.

Neste número, o leitor irá se deparar com a pluralidade e complexidade do pensamento psiquiátrico atual, fonte de nossa incansável busca e inquietação.

A avaliação dos programas de tratamento e dos serviços que trabalham com uso de subs-
Brian Rush, destacado professor de psiquiatria da universidade de Toronto. O autor enfatiza a necessidade de se buscar uma integração com outras áreas do conhecimento como, por exemplo, o auxílio da pesquisa a fim de se tornarem os programas e serviços melhores sucedidos em seus objetivos.

A relação temporal da Fobia Social e do Transtorno de pânico com dependência de substâncias psicoativas também é discutida por Mauro Terra e colaboradores.

A Escala de Mania de Altman poderá ser encontrada na versão em português, traduzida por Flávio Shansis e colaboradores, um interessante artigo para auxiliar os pesquisadores e estudiosos dos transtornos do humor.

Roosevelt Cassorla discute a necessidade de um processo de validação contínuo em Psicanálise e Psicoterapia, já que o analista é instrumento e parte do trabalho com sua contratransferência, incluindo o que chama de colocação em cena (Enactment).

Uma proposta psicoeducacional em grupos apoiada em Antonio Zabala é sugerida para pacientes adultos portadores de Déficit de Atenção e hiperatividade por Eugênio Grevet e colaboradores.

Lorena Geib e colaboradores revisam os aspectos atuais sobre as alterações e os distúrbios do sono no processo de envelhecimento.

Na sessão de saúde pública, encontramos dois interessantes artigos. Um de Heliete Karam focalizando seu estudo na influência do uso de estratégias coletivas de trabalho com a finalidade de apoiar, com o diálogo, sujeitos que são induzidos a práticas abusivas de alcoolização ou alcoolismo. Outro artigo de pesquisa de Raquel Deboni e Flávio Pechansky aborda a prevalência de tabagismo em uma unidade de internação psiquiátrica de Porto Alegre.

Finalizando esta edição, encontramos uma interessante entrevista com Carl Leukefeld, diretor do Center on Drug and Alcohol Research, assistente social, professor de Ciências do Comportamento, atuando nos Departamentos de Psiquiatria e Assistência social da Universidade de Kentucky. A entrevista foi realizada pelos membros do conselho editorial Antônio Marques da Rosa, Jair Knijnik com a colaboração de Elisabeth Meyer - Mestre em Psiquiatria e Jane L.W. Chachamovich - Assistente Social, Terapeuta de casais e família.

Desejamos a todos uma boa leitura e um FELIZ 2004.

$$
\text { Os editores }
$$

César Luís de Souza Brito e Jacó Zaslavsky 